Please do not remove this page

RMIT

UNIVERSITY

\title{
Variations in measured sound transmission loss due to sample size and construction parameters
}

Wareing, Robin; Davy, John; Pearse, John

https://researchrepository.rmit.edu.au/esploro/outputs/9921862180401341/filesAndLinks?institution=61RMIT_INST\&index=null

Wareing, R., Davy, J., \& Pearse, J. (2015). Variations in measured sound transmission loss due to sample size and construction parameters. Applied Acoustics, 89, 166-177.

https://doi.org/10.1016/j.apacoust.2014.10.001

Document Version: Accepted Manuscript

Published Version: https://doi.org/10.1016/j.apacoust.2014.10.001

Repository homepage: https://researchrepository.rmit.edu.au

(c) 2014 Elsevier Ltd. All rights reserved.

Downloaded On 2023/04/26 19:36:12 +1000

Please do not remove this page 
Thank you for downloading this document from the RMIT Research Repository.

The RMIT Research Repository is an open access database showcasing the research outputs of RMIT University researchers.

RMIT Research Repository: http://researchbank.rmit.edu.au/

\section{Citation:}

Wareing, R, Davy, J and Pearse, J 2015, 'Variations in measured sound transmission loss due to sample size and construction parameters', Applied Acoustics, vol. 89, pp. 166-177.

See this record in the RMIT Research Repository at:

https://researchbank.rmit.edu.au/view/rmit:28687

Version: Accepted Manuscript

Copyright Statement: (c) 2014 Elsevier Ltd. All rights reserved Creative Commons Attribution-

NonCommercial-NoDerivatives 4.0 International License.

Link to Published Version:

http://dx.doi.org/10.1016/j.apacoust.2014.10.001 


\section{Elsevier Editorial System(tm) for Applied Acoustics Manuscript Draft}

Manuscript Number:

Title: Variations in measured sound transmission loss due to sample size and construction parameters

Article Type: Research Paper

Section/Category: Europe and Rest of the World

Keywords: Sound insulation; sound transmission loss; size effect; niche effect

Corresponding Author: Mr. Robin Richard Wareing, BE(hons)

Corresponding Author's Institution: University of Canterbury

First Author: Robin Richard Wareing, BE(hons)

Order of Authors: Robin Richard Wareing, BE(hons); John R Pearse; John L Davy

Abstract: The compounding effects of sample size and sample construction on the measured sound transmission loss is assessed. The sound transmission loss of two different sized samples was evaluated for a wide range of different materials and constructions. The two sample sizes were; a 2400 $\mathrm{mm} \times 4800 \mathrm{~mm}$ sample that is compliant with IS015186-1 and a smaller non-compliant $1550 \mathrm{~mm} \times$ $950 \mathrm{~mm}$ sample. The samples tested were single and double leaf wall systems, with and without studs, made from a gypsum plasterboard, plywood, and vinyl mass-loaded barriers. The comparative results are presented with a discussion of the variations seen. Further testing is performed to quantify the effect of the room construction on the sound transmission loss. Finally a qualitative analysis is performed to assess the influence of various factors on the sound transmission loss. 
1

2

Variations in measured sound transmission loss due to sample size and construction parameters

Robin R. Wareing ${ }^{\mathrm{a}, *}$, John L. Davy ${ }^{\mathrm{b}}$, John R. Pearse ${ }^{\mathrm{a}}$

a University of Canterbury, Mechanical Engineering, Private Bag 4800, Christchurch 8140, New Zealand, robin.wareing@pg.canterbury.ac.nz, john.pearse@canterbury.ac.nz

b School of Applied Sciences, RMIT University, GPO Box 2476V Melbourne, Victoria 3001, Australia,john.davy@rmit.edu.au

${ }^{\mathrm{c}}$ CSIRO Materials Science and Engineering, PO Box 56 Highett Victoria 3190, Australia, john.davy@csiro.au

* Corresponding author. Tel.: +64277365899; E-mail address:

robin.wareing@pg.canterbury.ac.nz (R. R. Wareing)

Running Title: Effects of sample size and construction

\begin{abstract}
The compounding effects of sample size and sample construction on the measured sound transmission loss is assessed. The sound transmission loss of two different sized samples was evaluated for a wide range of different materials and constructions. The two sample sizes were; a $2400 \mathrm{~mm} \times 4800 \mathrm{~mm}$ sample that is compliant with ISO15186-1 and a smaller noncompliant $1550 \mathrm{~mm} \times 950 \mathrm{~mm}$ sample. The samples tested were single and double leaf wall systems, with and without studs, made from a gypsum plasterboard, plywood, and vinyl mass-loaded barriers. The comparative results are presented with a discussion of the variations seen. Further testing is performed to quantify the effect of the room construction on the sound transmission loss. Finally a qualitative analysis is performed to assess the influence of various factors on the sound transmission loss.
\end{abstract}

Keywords: Sound insulation; sound transmission loss; size effect; niche effect

\title{
1. Introduction
}

Research has shown that altering the size of a sound transmission loss sample can have a significant effect on the transmission loss below the critical frequency. In this paper the 
effects of altering both the sample size and the sample construction are investigated. It was found that the sample size has a significant effect on the measured sound transmission loss above and below the critical frequency. The construction of the sample was found to influence the variance caused by the changes in sample size. The influence of the sample construction on the amount of variation caused by changes to the sample size makes the development of any correction factors to allow for small sample results difficult.

There are two sample sizes specified by ISO10140-4 [1] for use in sound transmission loss testing. The larger size specified for testing wall systems is given as approximately $10 \mathrm{~m}^{2}$, and must be between $10 \mathrm{~m}^{2}$ and $20 \mathrm{~m}^{2}$. The smaller size is reserved for testing of small building elements such as windows and is $1250 \mathrm{~mm} \times 1500 \mathrm{~mm}\left(1.875 \mathrm{~m}^{2}\right)$. Preparation and testing of a full size $\left(10 \mathrm{~m}^{2}\right)$ transmission loss sample involves significant time and cost. Consequentially full sized wall testing is often prohibitively expensive for product development applications where a large number of samples are to be tested. This work focused on the evaluation of a small, $950 \mathrm{~mm} \times 1550 \mathrm{~mm}\left(1.4725 \mathrm{~m}^{2}\right)$, sound transmission loss test rig. This test rig is specifically designed for measuring the sound transmission loss a large number of samples quickly and efficiently in order to obtain comparative data.

Some prior research has been undertaken which investigates the effects of various laboratory parameters on the measured sound transmission loss. A more detailed examination of some of the articles presented in this section will be presented in the discussion section of this article. Important aspects of a sound transmission loss facility were found to be; the presence and depth of a sample niche [2-6], the sample size [7, 8], the size of receiving and source room [9, $10]$, the sample mounting conditions [2, 11-14], source and receiving room conditions [11, $15]$, and the construction of the sample $[10,16]$.

It is clear from the work presented by Kihlman and Nilsson [2], and Guy et al. [12] that the measured sound transmission loss is dependent on a number of interrelated parameters. These parameters were shown to interact to a large extent. Kihlman and Nilsson found that the high frequency (above coincidence) behaviour was independent of laboratory design and mounting conditions, whereas below the critical frequency the sound transmission loss depended on a range of different parameters. Guy et al. showed that the largest effects were due to the sample size and mounting conditions. It was also noted that changes to the sample size and mounting conditions could result in changes to the measured critical frequency. 
The measurement procedure can also have an effect on the measured sound transmission loss. The sound transmission loss values presented here were measured using the pressureintensity method as described in ISO 15186-1:2000 [17]. ISO 15186-1:2000 allows these measurements to be compared to measurements made using the pressure-pressure method (which is described in ISO 10140-2 [18] and ISO 10140-4). The sound transmission loss measured using the pressure-pressure and intensity methods have been compared experimentally [19]. It has been found that there are some variations between the measured results [20], especially at low frequencies [21, 22]. A major variation between the two methods is due to the fact that the pressure-pressure method measures the transmission loss of the entire wall system, including any baffles and mountings. Whereas the intensity method only measures the transmission loss of the sample scanned by the intensity probe. Despite the different method used, results found in this study should be comparative to the results presented by other authors who utilised the pressure-pressure method.

Theories for the prediction of sound transmission loss use different methods to account for the finite size of a real transmission loss sample. The original theories of sound transmission loss were based on an infinite panel system [23]. An infinite panel is inherently easier to predict the transmission loss of as the interaction at the edges and baffles adds complexity to any model of the system. These infinite panel models are adjusted and modified to accommodate finite sized panels [24-26]. It is accepted that altering the size of the sample will alter the natural frequencies of the sample and modify the effective panel impedance and the transmission loss of a sample is increased below the critical frequency as the sample size is decreased [12].

The results of testing the same sample in a small test rig $\left(1.5 \mathrm{~m}^{2}\right)$ and a large test rig $\left(11.6 \mathrm{~m}^{2}\right)$ are presented and discussed. The reasons for variations seen between the two were investigated using further testing and comparison of various relevant prediction methods. The purpose of the small transmission loss facility is comparative testing for which it is helpful if the general trends in the results of the small sample match those of the large sample.

\section{Sound Transmission Loss Tests}

A range of samples were tested in both transmission loss facilities; the samples tested included single leaf plywood panels, single leaf gypsum plasterboard panels, twin leaf gypsum plasterboard walls and twin leaf plywood walls. In total nine small samples and nine large samples were tested. The samples tested varied significantly in material properties and 
overall construction. The construction was found to have a large effect on the variation in the measured transmission losses for the different sample sizes.

The large samples were mounted between a $220 \mathrm{~m}^{3}$ reverberation room and a $200 \mathrm{~m}^{3}$ semianechoic space. The small sample was mounted between the same reverberation room and a 9 $\mathrm{m}^{3}$ semi-anechoic space. The surface area of the large receiving room is $236 \mathrm{~m}^{2}$, and the surface area of the small receiving room is $27 \mathrm{~m}^{2}$.

The large samples were constructed on a standard timber frame, which was mounted in 2400 $\mathrm{mm} \times 4800 \mathrm{~mm}$ test aperture between the source room and the receiving room. The total depth of the aperture was $700 \mathrm{~mm}$. The timber frame stud spacing was $600 \mathrm{~mm}$ and the stud depth was $75 \mathrm{~mm}$. The single leaf panels were attached to the receiving room side of this wall. The double leaf systems were also constructed on this frame with cavity absorption added. The effective source room niche depth was $550 \mathrm{~mm}$ for the single leaf systems, and $410 \mathrm{~mm}$ for the double leaf wall systems.

The small sample was clamped into a $1550 \mathrm{~mm} \times 950 \mathrm{~mm}$ aperture, in the manner shown in Figure 1. The single leaf samples were clamped into the frame with no modifications. The double leaf systems were constructed as complete components with the same dimensions as the frame and similar sized stud spacing as the large system. The effective source room niche depth for both single and double leaf panels was $350 \mathrm{~mm}$.

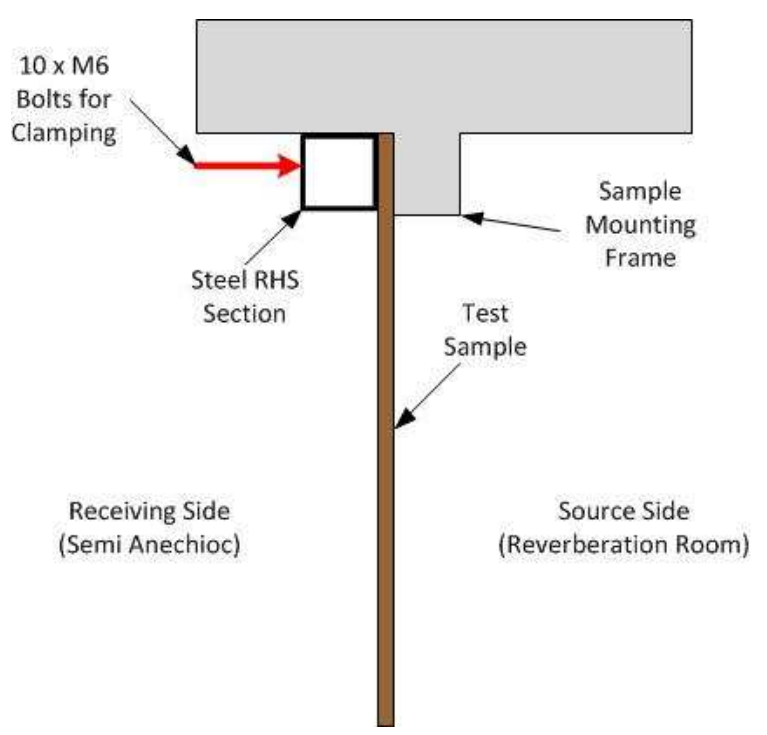

Figure 1: Small sound transmission loss clamp and frame arrangement. 

intensity probe was held at a distance of approximately $150 \mathrm{~mm}$ from the wall and a scan spacing of approximately $200 \mathrm{~mm}$ was used. Five microphones were used to measure the sound pressure level within the reverberation room. The intensity and sound pressure level values allow the sound transmission loss to be calculated. The measurements were sufficiently repeatable within the $100 \mathrm{~Hz}$ to $5000 \mathrm{~Hz}$ frequency range.

The small samples were measured in a similar manner, but the scan spacing was reduced to approximately $100 \mathrm{~mm}$. This reduced the overall scan time length, thus the averaging time was reduced accordingly. This method was sufficiently repeatable within the same $100 \mathrm{~Hz}$ to $5000 \mathrm{~Hz}$ frequency range presented. The repeatability of the small transmission loss tests was somewhat worse than that of the large transmission loss tests, but it was still within acceptable tolerances.

The sound transmission loss was measured for four thicknesses of plywood (7 mm, $9 \mathrm{~mm}, 12$ $\mathrm{mm}$, and $21 \mathrm{~mm}$ ); in different arrangements of wall system. Figure 2 shows the transmission loss of single leaves of $7 \mathrm{~mm}$ and $9 \mathrm{~mm}$ plywood measured in both the small and large transmission loss rigs. Figure 3 presents the sound transmission loss of single and double leaf $12 \mathrm{~mm}$ plywood panels. The sound transmission losses of various arrangements of $21 \mathrm{~mm}$ plywood are presented in Figure 4.

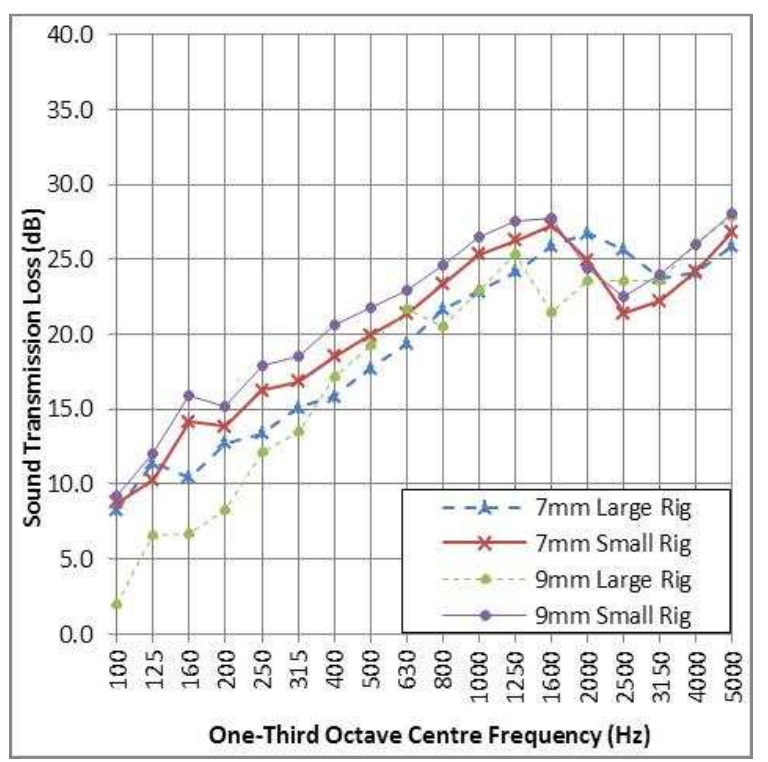


Figure 2: Sound transmission loss of $7 \mathrm{~mm}$ and $9 \mathrm{~mm}$ plywood samples. The large samples were single leaf panels supported by a timber stud frame. The small samples were clamped, unsupported panels.

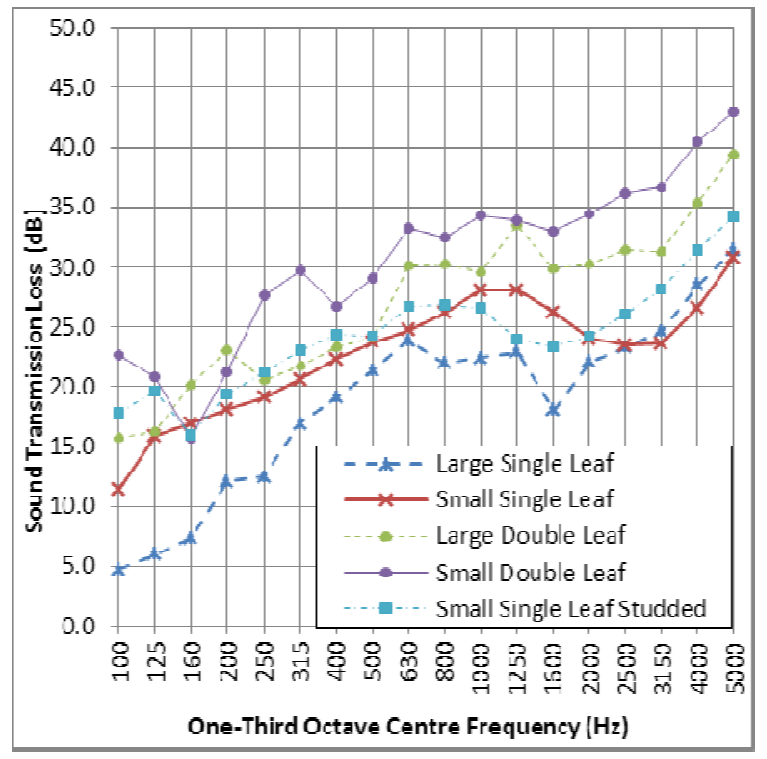

Figure 3: Sound transmission loss $12 \mathrm{~mm}$ plywood panels, in both single and double leaf arrangements. In the single leaf samples the large samples were single leaf panels supported by a timber stud frame, and the small samples were clamped, unsupported panels. In the double leaf samples both samples were supported by a timber stud frame.

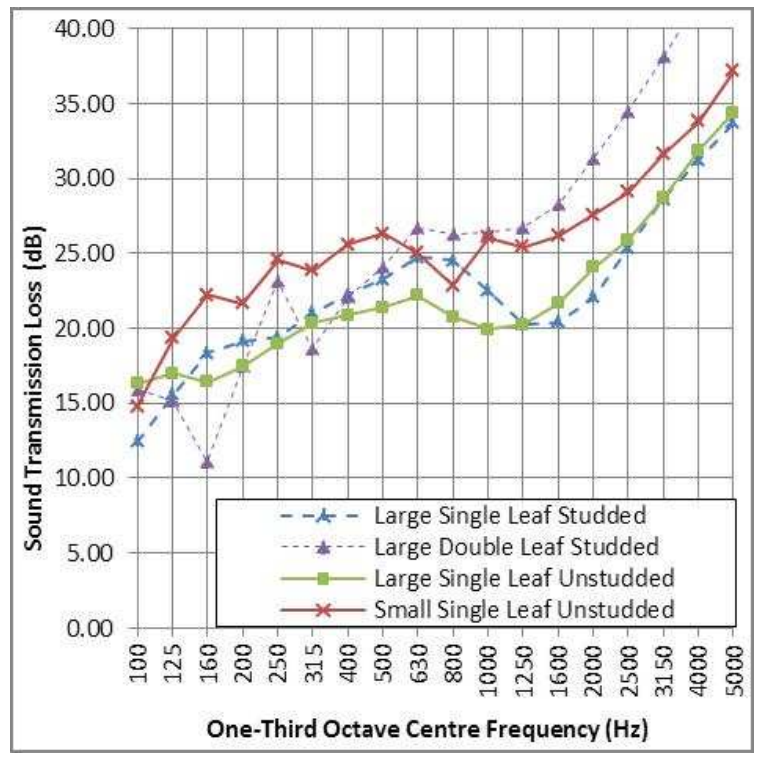


Figure 4: Sound transmission loss of $21 \mathrm{~mm}$ plywood samples measured in small and large test rigs. The un-studded large panel was taped and glued at the joints. The studded samples were built on the original timber frame.

In all the single leaf samples the smaller sample size was found to result in a consistently higher sound transmission loss across the entire frequency range. The variation is generally greater than $5 \mathrm{~dB}$ below the critical frequency. The difference is reduced at and above the critical frequency. The larger sample size had a less severe coincidence dip than the small sample; resulting in convergence of the transmission loss curves near the critical frequency.

The same general trends were seen in the measured transmission loss of a single leaf of 10 $\mathrm{mm}$ gypsum plasterboard (Figure 5) as seen in the plywood panels and in the measured transmission loss of a $2 \mathrm{~kg} / \mathrm{m}^{2}$ mass loaded limp barrier (Figure 6). The transmission loss of the smaller panel was significantly higher below the critical frequency. The measured transmission losses were seen to converge near the critical frequency. Above the critical frequency a divergence occurs with the small sample having a higher transmission loss than the large sample. The convergence at coincidence of the gypsum plasterboard was more significant in the case of the single leaf sample.

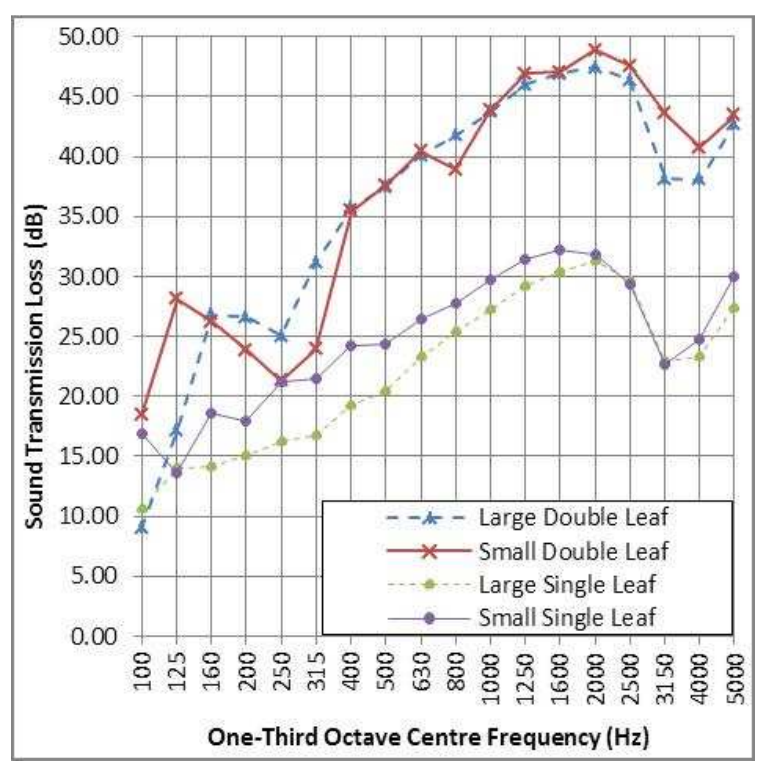


Figure 5: Sound transmission loss of 10mm gypsum plasterboard samples measured in small and large test rigs. The large sample is a single leaf supported by a timber stud frame. The small sample is a clamped, unsupported panel.



Figure 6: Sound transmission loss of $2 \mathrm{kgm}^{-2}$ mass loaded barrier samples in small and large test rigs. Both the samples were glued and stapled around the edges.

When the single leaves were clamped into the test rig there are no studs providing stiffness. In order to assess the effect that studs may have on the measured transmission loss a small studded wall sample was constructed with an effective stud spacing of $475 \mathrm{~mm}$ and a stud depth of $75 \mathrm{~mm}$. A single $12 \mathrm{~mm}$ plywood sheet was screwed to the small studded frame and clamped into the small test rig, the results of which are also presented in Figure 3. The small test sample with studs present also has a higher sound transmission loss across much of the measured frequency range, although the variation between the small and large rigs is less consistent when the studs are present.

Two small double leaf studded wall were also tested; the sound transmission loss of these small samples are compared to the corresponding large transmission loss and the single leaf samples in Figures 3 and 5. In the double leaf system the small sample has a higher sound transmission loss across the majority of the frequency range. This variation is less consistent than in the case of single leaf panels. 
The effect that the studs have on the variation in measured sound transmission loss was further assessed by removing the studs from the large transmission loss sample; leaving the panel only supported at the perimeter. This allowed an unsupported $21 \mathrm{~mm}$ plywood wall to be constructed and tested. The results of this test are compared to the double and single leaf samples in Figure 4. The joints between the individual plywood sheets were glued and taped to seal any leakage. The same trends in the transmission loss are shown in these measurements, with the smaller sample having a higher sound transmission loss across most of the frequency range.

The variation in the measured sound transmission loss is slightly greater for the smaller test rig. This may be due to the reduced scan time and a reduction in the number of scan passes of the panel, which results in a smaller space-time average. The smaller sample is also affected more by any variations in the material, construction or edge conditions. Variations in these parameters can result in localised zones of high or low sound transmission loss; this will affect the repeatability of the measured sound transmission loss.

\section{Panel Surface and Source Room Sound Pressure Levels}

To investigate if other factors were affecting the measured sound transmission loss of the samples the variation in the sound pressure level within the source room and the variation in sound pressure level across the surface of the sample was investigated. The results of these tests indicated that the pressure variations on the source room side were not major contributors to the variations in measured sound transmission loss.

The sound pressure level was measured at the surface of both the small and large transmission loss samples. This was achieved by placing the face of a microphone near the surface of the sample, and performing sound pressure level measurements on a grid across the sample surface. These measurements were performed to assess the effect the smaller sample size and the arrangement of the test facilities had on the uniformity of the pressure distribution across the surface.

The small panel was tested using a 45 point scan. The pressure level was measured at two locations; at the surface of the panel and $25 \mathrm{~mm}$ from the surface of the panel. The measurements were made in a $185 \mathrm{~mm}$ by $220 \mathrm{~mm}$ grid. A 72 point scan was utilised to assess the pressure at the surface of the large panel. The large panel was measured in a 400 $\mathrm{mm}$ by $400 \mathrm{~mm}$ grid with the microphones $25 \mathrm{~mm}$ from the surface of the panel. These 
measurements will be affected by the $3 \mathrm{~dB}$ increase that is seen near a surface. The measurements remain useful for assessing the variation across the surfaces.

The variance in the measured sound pressure level $25 \mathrm{~mm}$ from the surface of the panel was evaluated for both the small and the large test rigs and is presented in Figure 7. The small sample has a larger variance in the sound pressure level near the surface than the large sample in the $125 \mathrm{~Hz}-400 \mathrm{~Hz}$ one third octave bands, with the large sample having a higher variance in the rest of the measured frequency range. There is no clear trend relating the variance of the pressure levels across the surface of the panels to the variations in the measured sound transmission loss behaviour. The large test rig has a relatively consistent pressure level across the surface at the lower frequencies. At higher frequencies there is an increased variation across the surface which is the result of an increase in the measured sound pressure level near the edges of the panel.

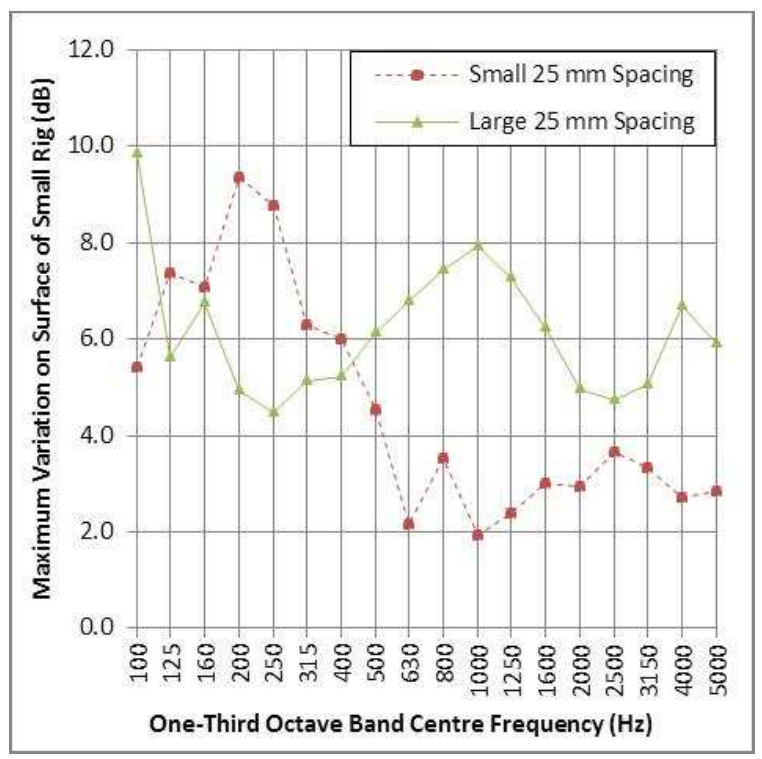

Figure 7: Maximum difference in sound pressure levels measured in grid across the surface of both test samples at a distance of $25 \mathrm{~mm}$.

The small test rig has a large variation at the low frequencies $(<400 \mathrm{~Hz})$, due to resonant behaviour caused by the tunnel on the source side of the panel. Above $400 \mathrm{~Hz}$ the variation in the sound pressure level is much lower, as is expected as the modal density within the tunnel increases. 
Overall the level of variation was relatively consistent across the frequency range and between the different sample sizes. The variation in sound pressure level was also not directly correlated with changes in the measured sound transmission loss. This indicates that the variation in the pressure level across the surface is not a major contributor to the variation in the measured sound transmission loss.

The difference between the average sound pressure level measured at $25 \mathrm{~mm}$ from the surface of both samples is presented in Figure 8. The difference in average sound pressure level is below $2.5 \mathrm{~dB}$ across the frequency range measured. This does not appear to account sufficiently for the variation seen in the sound transmission loss measurements performed.

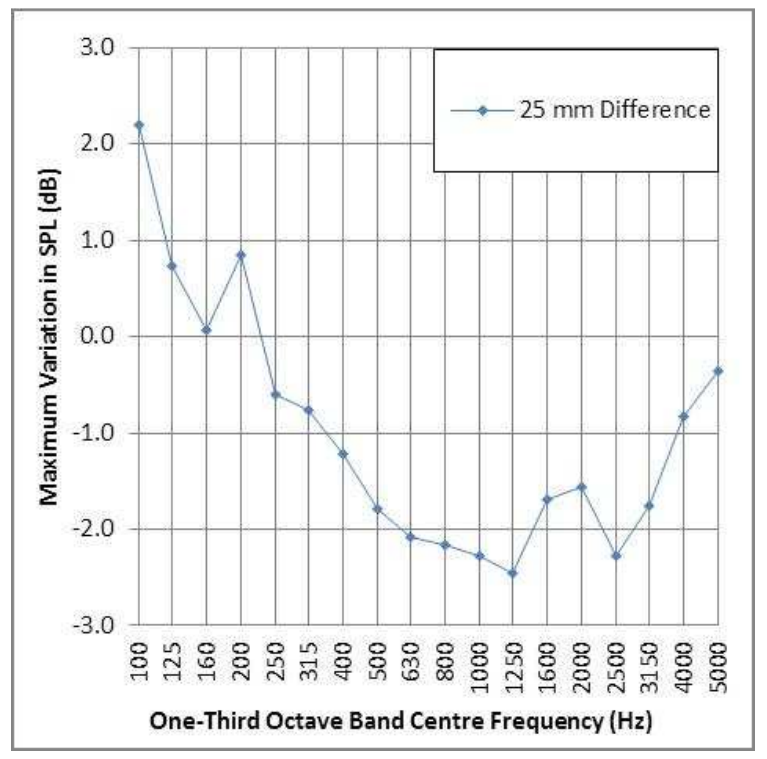

Figure 8: Variation between averaged sound pressure levels measured $25 \mathrm{~mm}$ from the surface of the small and large transmission loss rigs.

A survey of the sound pressure level throughout the reverberation room was undertaken, using a $500 \mathrm{~mm} \times 500 \mathrm{~mm} \times 500 \mathrm{~mm}$ three dimensional array of measurement positions. A comparison between the sound pressure level throughout the room and the sound pressure level within $500 \mathrm{~mm}$ of the sound transmission loss samples is presented in Figure 9. This shows a relatively minor variation between the pressure near the surface of the samples and the pressure throughout the room. There were no large variations in the sound pressure levels within the reverberation room, except in measurements very close to the source. In the presented data microphones within $1.4 \mathrm{~m}$ of the source have been neglected. This indicates 
that the sample location was not a major contributor to the variations in measured sound transmission loss

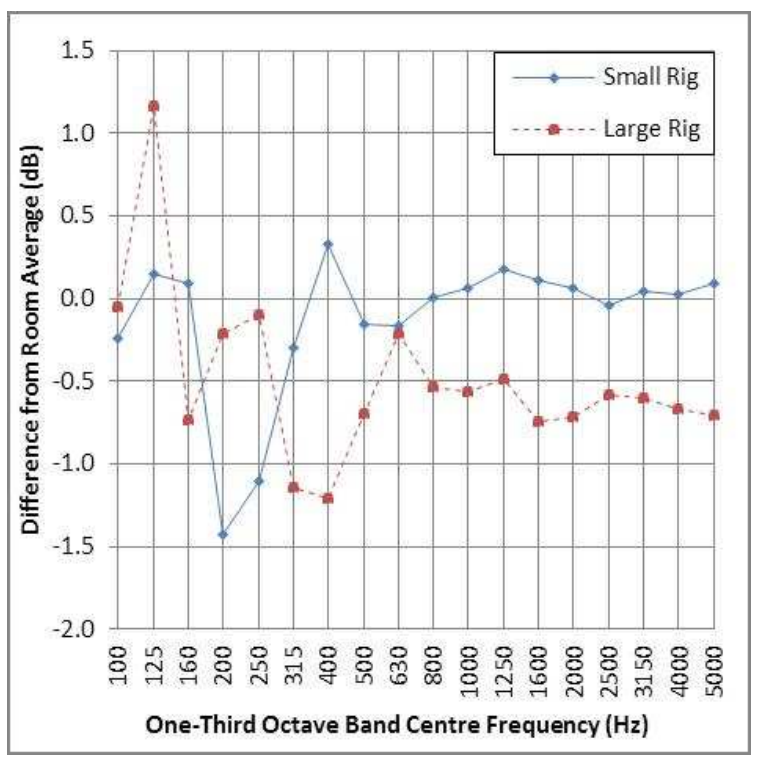

Figure 9: Variation between average sound pressure level $300 \mathrm{~mm}$ from the surface of the test samples and the average sound pressure level throughout the reverberation room.

\section{Variation due to sample size}

There is an obvious change in the measured sound transmission loss as the sample size is altered. This section will explore some of the possible reasons for this variation based on theoretical principles and previous research.

Altering the size of the test sample alters the edge ratio and the ratio of the sample size to the source wall size. The different edge ratios and source wall area percentages are presented in Table 1. Kihlman and Nilsson [2] describe some of the effects that the changes to the wall area and edge ratios have on the sound transmission loss. The variations seen in the measurements presented tend to agree with the results from Kihlman and Nilsson below the critical frequency. Above the critical frequency Kihlman and Nilsson predicted there would be no changes due to the sample size and mounting conditions, which is contradictory to the results presented here.

Table 1: Edge ratio and wall area ratio of small and large samples 


\begin{tabular}{|l|l|l|}
\hline $\begin{array}{l}\text { Edge Ratio: } \\
\frac{l_{\text {edge }}(m)}{A_{\text {panel }}\left(m^{2}\right)}\end{array}$ & 3.4 & 1.3 \\
\hline $\begin{array}{l}\text { Wall Area Ratio: } \\
\frac{A_{\text {panel }}\left(m^{2}\right)}{A_{\text {wall }}\left(m^{2}\right)}\end{array}$ & 0.06 & 0.3 \\
\hline
\end{tabular}

The behaviour of the sample above, near and below the coincidence region is governed by different factors [27]. Within each of these frequency ranges the size of the sample affects the measured transmission loss in different ways. Each of these regions must be considered individually when evaluating any effects the sample size has on the measured sound transmission loss. In all the measured cases except the twin leaf gypsum plaster board, the small sample has a higher sound transmission loss across the majority of the frequency range. In general the sound transmission loss curves tend to converge near the coincidence frequency. Above the coincidence frequency the sound transmission loss curves generally diverge again with the small sample having a higher measured sound transmission loss.

In the region below the coincidence frequency the sound transmission loss is governed by the mass of the sample [28]. The resonant transmission in this range is heavily affected by the edge effects as the edges are comparatively efficient radiators. Thus at low frequencies the panel size and edge conditions are of significant importance to the overall measured sound transmission loss. A number of studies have shown [7, 8] that the sound transmission loss of a sample will increase as the panel size is reduced. Although these studies were focused on the sound transmission loss measured using the pressure-pressure method, the theoretical foundation holds and agrees with the results measured in this study.

Around the critical frequency very little information has been presented on the change caused by altering the sample size. When the coincidence occurs the panel radiates sound highly efficiently, this means the panel itself becomes the dominant radiator and the contributions from edge effects are reduced. The size effects are similarly related to the panel's transmission efficiency and as such the very high efficiency that occurs at coincidence causes the size effects to become negligible.

Above the critical frequency the edges provide a link for power to flow into the surrounding structures. This power flow is described in a number of previous studies [2, 29]. The flow of power from the sample into the surrounding structure is heavily dependent on the connection between the sample and the structure. All structural connections will provide some level of 
energy dissipation, with an optimal dissipation frequency based on the stiffness and damping of the system. A more effective coupling will result in a higher sound transmission loss as a greater quantity of the panels vibrational energy will be dissipated into the surrounding structure. This effect is most pronounced for relatively heavy walls, but is also present in lightweight walls [30], although the glass used in their testing will have very low damping compared to plywood or plasterboard. The results presented in this paper indicate that the sample size can have a large effect on the measured sound transmission loss above the critical frequency.

The construction of the sample was shown to significantly affect the influence of sample size on the measured sound transmission loss. Reducing the size of a single leaf wall system caused an increase in the measured sound transmission loss in most of the one-third octave bands measured. The same reduction in size for a double leaf, studded wall system resulted in much less variation in the measured sound transmission loss. This indicates that the structure of the test sample affects the samples sensitivity to changes in the sample size. The addition of studs adds an alternative high radiation area and structural connection path below the critical frequency, which is provided only by the edges of the sample in the case of nonstudded walls. This added radiator reduces the influence of the edge ratio on the measured sound transmission loss.

\section{Variation due to other effects}

The depth of the measurement niche may have an effect on the measured sound transmission loss. The scale of the niche effect is influenced by the interaction of a number of conditions and parameters in each test. The primary factors are the shielding of the test element from grazing waves, the arrangement of the mounting baffle, and resonant behaviour within the niche.

The exposure of the panel to waves at grazing incidence is directly affected by the depth of the niche on the reverberant source room side. As the niche depth increases the maximum angle of incidence is reduced. This yields an expression for the maximum angle of incidence $\left(\theta_{\max }\right)$, given by Equation 1. Theoretically the predicted sound transmission loss of an infinite plate is heavily dependent on the angle of incidence. In the case of the single leaf samples the maximum angles of incidence are given in Table 2. The reduced angle of incidence will result in an increased sound transmission loss, as predicted by the infinite panel theories. This is due to grazing waves being responsible for a significant proportion of 
the transmitted sound. This basic explanation accounts for some of the variation in sound transmission loss seen in these measurements.

$$
\theta_{\max }=\tan ^{-1}\left(\frac{L_{x}, L_{y}}{d}\right)
$$

Equation 1

where $L_{x}$ and $L_{y}$ are the lengths of the rectangular sample and $d$ is the depth of the sample niche.

Table 2: Maximum angle of incidence on reverberation (source) room side of transmission loss sample.

\begin{tabular}{|l|l|l|}
\hline Sample & Horizontal $\vartheta_{\max }$ & Vertical $\vartheta_{\max }$ \\
\hline Large $(4.8 \mathrm{~m} \times 2.4 \mathrm{~m})$ & $83^{\circ}$ & $77^{\circ}$ \\
\hline Small $(1.5 \mathrm{~m} \times 0.95 \mathrm{~m})$ & $77^{\circ}$ & $69^{\circ}$ \\
\hline
\end{tabular}

Existing research into the effect the niche has on the sound transmission loss has been explored using numerical [31] and wave based methodologies [4]. This research comes to the same general conclusion that the sound transmission loss is decreased below the coincidence frequency as the niche depth is increased. The niche depth of the large sample is significantly larger than that of the small sample, this may have contributed to the decrease in measured sound transmission loss of the large sample below the critical frequency. Above the critical frequency the transmission loss was seen to decrease as the niche depth was increased. The niche effect is also much more evident in samples smaller than $5 \mathrm{~m}^{2}$ [5], as is the case with the small sample tested in this research. The behaviour measured in this research supports this conclusion and this niche effect may be a major contributor to the variations seen in the measured sound transmission loss.

Further research has been undertaken on the tunnelling effect that occurs when there is a niche on both sides of the panel [6]. In this research it was shown that the position of a sample within the aperture can have a significant influence on the measured sound transmission loss. The trends of increasing sound transmission loss with increasing tunnel depth and decreasing panel size appear to be somewhat contradictory to the results presented here. The smaller transmission loss rig has a shallower niche, but has a higher sound transmission loss. The most likely reason for this discrepancy is the influence of other factors, namely the panel size affecting the results to a greater level.

The method used to secure the sample into the test opening can affect the measured sound transmission loss. This is especially important at low frequencies where the majority of the 
sound is radiated at the boundaries of the sample [13]. Furthermore the physical construction of the test opening can also have an effect on the measured sound transmission loss. It has been shown that increasing the rigidity of the mounting condition will increase the sound radiation near the edges. The radiation efficiency for a clamped panel is twice as large as that of a simply supported panel [14]. The difference in measured sound transmission loss can differ by up to $3 \mathrm{~dB}$ between the different fixture arrangements [30].

The inclusion of the stud frame stiffens the panel which in turn alters the radiation efficiency of the panel. The effect of stiffening members on the radiation efficiency of panels has been explored by Maidanik [16]. In his research it was shown that the inclusion of studs results in areas of increased radiation efficiency around the studs. The radiation efficiency below the coincidence frequency is proportional to the perimeter of the boundary of a finite panel. This effect is due to the edges causing a scattering of the plane waves within the panel, resulting in wave components within the panel that may effectively radiate sound. The presence of the studs has the same scattering effect, increasing the radiation efficiency of studded walls. The increase in the radiation efficiency of studded walls due to the presence of the studs reduces the difference in measured sound transmission loss between the small and large test samples by reducing the relative effect the change in edge ratio caused.

The measurements reported here were made on samples with different mounting conditions and methods. The large samples were screwed to the timber studs, whereas the small samples were clamped into the test aperture. It is likely that these two edge conditions had similar behaviour in respect to the measured sound transmission loss. The screwed attachment may be slightly less rigid than the clamped method, but the screwed samples were also glued around the edges adding further rigidity.

All the double leaf samples were constructed on a timber stud frame. The majority of the single leaf samples tested had studs present for the large samples, and were freely supported in the small samples. The inclusion of studs within the test sample increases the overall stiffness of the system. The unsupported area of the small sample was $1550 \mathrm{~mm} \times 950 \mathrm{~mm}$, whereas when the studs are included the unsupported area in a large sample was $600 \mathrm{~mm} \times$ $2400 \mathrm{~mm}$. The inclusion of studs into the test system has some effect on the transmission loss of the large facility as shown in Figure 10. The presented data compares a single leaf of plywood measured with and without studs in the large transmission loss rig.

\section{Conclusions}


The results presented in this paper show good qualitative agreement with the existing theories on the effects of sample size below the coincidence frequency. The smaller sample size results in a sound transmission loss that is measured to be approximately $5 \mathrm{~dB}$ higher below the critical frequency. The sound transmission loss is seen to converge around the critical frequency, which is also predicted by theoretical approaches.

The measurements deviate from previous research on the effects of sample size above the coincidence frequency. In this higher frequency range the smaller sample is seen to have a significantly higher sound transmission loss, in the order of $3-5 \mathrm{~dB}$. This is not predicted by the current theories on the effects of sample size. This effect may be explained as a result of several factors; the higher edge ratio resulting in greater energy loss via coupling to the frame, the decreased niche depth in the smaller sample, and the reduction of waves at near grazing incidence because of the frame. It is presumed that these effects combine to increase the measured sound transmission loss above the coincidence frequency.

The sample construction was seen to have a large effect on the variation caused by changes in sample size. Reducing the sample size of a studded wall (either single or double leaf) had a diminished effect on the measured sound transmission loss when compared to the same size change for a wall without studs. This must be accounted for when performing measurements in reduced size transmission loss suites. Data from smaller samples cannot be directly compared to full size data without an understanding of the influence that the sample construction has on the size effects.

\section{References}

1. ISO, ISO 10140-4:2010, in ISO Acoustics -- Laboratory measurement of sound insulation of building elements -- Part 4: Measurement procedures and requirements. 2010. p. 1-12.

2. Kihlman, T. and A.C. Nilsson, The effects of some laboratory designs and mounting conditions on reduction index measurements. Journal of Sound and Vibration, 1972. 24(3): p. 349-364.

3. Sakuma, T., K. Adachi, and Y. Yasuda. Numerical investigation of the niche effect in sound insulation measurement. in INTER-NOISE and NOISE-CON Congress and Conference Proceedings. 2011. Institute of Noise Control Engineering.

4. Dijckmans, A. and G. Vermeir, A wave based model to predict the niche effect on sound transmission loss of single and double walls. Acta Acustica united with Acustica, 2012. 98(1): p. 111-119.

5. Vinokur, R., Mechanism and calculation of the niche effect in airborne sound transmission. The Journal of the Acoustical Society of America, 2006. 119(4): p. 2211-2219. 
6. Kim, B.-K., et al., Tunneling effect in sound transmission loss determination: Theoretical approach. The Journal of the Acoustical Society of America, 2004. 115(5): p. 2100-2109.

7. Michelsen, N., Effect of size on measurements of the sound reduction index of a window or a pane. Applied Acoustics, 1983. 16(3): p. 215-234.

8. Yoshimura, J., S. Sugie, and E. Toyoda. Effects of size and edge damping on measurement results for sound reduction index of glass pane. in INTER-NOISE and NOISE-CON Congress and Conference Proceedings. 2006. Institute of Noise Control Engineering.

9. Bhattacharya, M. and R. Guy, The influence of the measuring facility on the measured sound insulating property of a panel. Acta Acustica united with Acustica, 1972. 26(6): p. 344-348.

10. Price, A. and M.J. Crocker, Sound transmission through double panels using statistical energy analysis. Journal of the Acoustical Society of America, 1970. 47: p. 683.

11. Nilsson, A., Reduction index and boundary conditions for a wall between two rectangular rooms. Part I: Theoretical results. Acta Acustica united with Acustica, 1972. 26(1): p. 1-18.

12. Guy, R., A. De Mey, and P. Sauer, The effect of some physical parameters upon the laboratory measurements of sound transmission loss. Applied Acoustics, 1985. 18(2): p. 81-98.

13. Berry, A., J.L. Guyader, and J. Nicolas, A general formulation for the sound radiation from rectangular, baffled plates with arbitrary boundary conditions. Journal of the Acoustical Society of America, 1990. 88: p. 2792.

14. Leppington, F., E. Broadbent, and K. Heron, Acoustic radiation from rectangular panels with constrained edges. Proceedings of the Royal Society of London. A. Mathematical and Physical Sciences, 1984. 393(1804): p. 67-84.

15. Nilsson, A., Reduction index and boundary conditions for a wall between two rectangular rooms. Part II: Experimental results. Acta Acustica united with Acustica, 1972. 26(1): p. 19-23.

16. Maidanik, G., Response of ribbed panels to reverberant acoustic fields. the Journal of the Acoustical Society of America, 1962. 34(6): p. 809-826.

17. ISO, ISO 15186-1:2000, in Acoustics -- Measurement of sound insulation in buildings and of building elements using sound intensity -- Part 1: Laboratory 2000. p. 1-20.

18. ISO, ISO 10140-2:2010, in ISO Acoustics -- Laboratory measurement of sound insulation of building elements -- Part 2: Measurement of airborne sound insulation. 2010. p. 1-13.

19. Van Zyl, B., P. Erasmus, and G. van der Merwe, A comparative study of the classic method and the sound intensity method for determining sound insulation. NPRL

Report FIS 320 Council for Scientific and Industrial Research, Pretoria, Republic of South Africa, 1985.

20. Jonasson, H.G., Sound intensity and sound reduction index. Applied Acoustics, 1993. 40(3): p. 281-293.

21. Van Zyl, B., P. Erasmus, and F. Anderson, On the formulation of the intensity method for determining sound reduction indices. Applied Acoustics, 1987. 22(3): p. 213-228.

22. Halliwell, R. and A. Warnock, Sound transmission loss: Comparison of conventional techniques with sound intensity techniques. Journal of the Acoustical Society of America, 1985. 77(6): p. 2094-2103.

23. Cremer, L., Theorie der schalldämmung wände bei schrägem einfall. Akustische Zeitschrift., 1942. 7: p. 81-104. Most of this article has been republished with an 
English language summary in: Northwood, T. D. (1977). "Theory of the sound attenuation of thin walls with oblique incidence," in Architectural Acoustics, Benchmark Papers in Acoustics Vol. 10, edited by T. D. Northwood Dowden, Hutchinson and Ross, Stroudsburg, PA, pp. 367-399.

24. Davy, J.L., Predictiong the sound insulation of single leaf walls: Extension of Cremer's model. Journal of the Acoustical Society of America, 2009. 126(4): p. 18711877.

25. Sewell, E., Transmission of reverberant sound through a single-leaf partition surrounded by an infinite rigid baffle. Journal of Sound and Vibration, 1970. 12(1): p. 21-32.

26. Hansen, C.H. Effect of size on the sound transmission loss of both heavily and lightly damped orthotropic panels. in INTER-NOISE Conference Proceedings. 1991. Institute of Noise Control Engineering.

27. Bies, D.A. and C.H. Hansen, Engineering noise control. 2nd ed. 1996, Cornwall: TJ Press (Padstow) Ltd. 736.

28. Hopkins, C., Sound insulation. 2012: Routledge. 622.

29. Kihlman, T., Sound transmission in building structures of concrete. Journal of Sound and Vibration, 1970. 11(4): p. 435-445.

30. Utley, W. and B. Fletcher, Influence of edge conditions on the sound insulation of windows. Applied Acoustics, 1969. 2(2): p. 131-136.

31. Tetsuya, S., Numerical Investigation of the Niche Effect in Sound Insulation Measurement. Inter-noise 2011, INCE, 2011. 